\title{
The Epping jaundice outbreak: a 24 year follow up
}

\author{
A J Hall, J M Harrington, J A H Waterhouse
}

\begin{abstract}
Study objective-The aim was to trace 84 cases of jaundice that occurred following accidental ingestion of methylene dianiline (MDA) in Epping in 1965, and to look at long term health effects.

Design-The original case notes of the cases were used to identify the patients. Subsequent tracing procedures included local general practitioners, the Central NHS Registry, electoral rolls, and company records.

Setting-This was a community based survey.

Main results-The health status of 68 (81\%) of the group was established with 18 deaths. Of the 50 cases known to be alive, $58 \%$ completed a health questionnaire. The causes of death were unremarkable except for one case of carcinoma of the biliary tract. Two surviving cases had suffered retinal pathology. Four other surviving cases had had a further, perhaps unrelated, episode of jaundice.

Conclusions-Although the dose and route of administration in the epidemic differed from occupational exposure, this follow up study a generation on provides little, if any, evidence of long term health sequelae. Nevertheless, in the absence of well documented exposure and health effects data, such accidental poisonings with proven animal carcinogens warrant long term follow up. The identified cohort will be the subject of further study.
\end{abstract}

f Epidemiol Community Health 1992; 46: 327-328

In February 1965, a medical student reported sick with a history of severe upper abdominal pain of two days' duration which was followed by mild jaundice. This was the index case of what proved to be an outbreak of jaundice in the Epping district of Essex which affected 84 people. The report ${ }^{1}$ traced a common source for the illness to the consumption of a particular type of wholemeal bread. The flour used to make this bread had been accidentally contaminated in transit with 4,4'methylene dianiline (MDA), an epoxy resin hardening agent. At that time, no previous record of human poisoning with MDA had been reported, though animal experiments with unused wholemeal flour produced hepatic changes similar to the observed human effects. These were portal inflammation, eosinophilic infiltration, cholangitis, cholestasis, and varying degrees of hepatocellular damage. ${ }^{2}$

Subsequent animal studies have confirmed the hepatotoxic properties of MDA and have also shown that this aromatic amine causes hepatocellular carcinoma following oral administration. In addition, MDA is now known to be mutagenic and in 1986 the International Agency for Research on Cancer (IARC) classified MDA as a proven animal carcinogen. ${ }^{3}$ However, as few human exposure and health effects data have been reported, it seemed a worthwhile exercise to try and follow up, a generation later, the individuals who suffered from the only episode of acute intoxication with MDA in the medical literature. The follow up period was long enough to look for carcinogenic effects but would also provide an opportunity to study any long term morbidity following the initial hepatotoxic episode.

\section{Methods}

The first step in the process of tracing the 84 individuals was to enlist the help of the original investigator, Dr Harry Kopelman. He willingly agreed to provide the original case notes and the 84 cases were soon identified. Unfortunately, vital stastistical information such as date of birth was lacking in half the cases, while a last known address was only present in $80 \%$.

The small number of cases who could readily be traced was supplemented by information gleaned from the Office of Population Censuses and Surveys (OPCS), the National Health Service central registry (NHSCR), family practitioner committees, electoral rolls, and hospital records, as well as professional registries and company records.

For those individuals who were identified as being still alive, an attempt was made, with the permission of the relevant family practitioner committee, to approach the general practitioner with a view to administering a short questionniare to the survivors. Where that permission was granted, a letter requesting an interview was mailed. The questionnaire inquired about cigarette, coffee, and alcohol consumption, as well as diet, current and past health, and occupation.

For those individuals who were identified as dead, a cause of death, coded by the OPCS, was obtained. Although the number of deaths was small, an observed:expected ratio was calculated using the life table method and adjusted for the age distribution of the original population. One sided Poisson distribution tests of significance were calculated.

\section{Results}

The current status of the original 84 cases is outlined in table I. As the subsequent analysis of deaths was limited to those individuals who died aged less than 90 years, one female was excluded from the mortality analysis. 
ALIVE CASES

Fifty cases were known to be alive and of these 22 were personally interviewed, five completed a postal questionnaire, and the next of kin returned a individuals refused to participate, and tracing difficulties accounted for the rest. The mean age of the responders was 69 years, with 18 females and 11 males. Thirty eight per cent had been admitted to hospital at the time of the original episode with jaundice. Most $(90 \%)$ never ate that type of bread again! Eight $(27.5 \%)$ were current smokers, most $(75-80 \%)$ were tea and/or coffee drinkers, and two were vegetarians. Eight individuals were currently following special diets (low fat, high fibre, etc). Ten cases $(45 \%)$ had some form of allergy, mainly asthma or hay fever. Eleven cases had some notable pathology but none had more than one disorder. Of relevance to this study, one each had gall stones, Crohn's disease, and stomach ulcer. One individual had had hepatitis B before 1965 and four others indicated that they had had jaundice since the episode. These episodes may have been hepatitis A-certainly one case caught hepatitis A from her daughter following her return from India.

All but two of the cases were socioeconomic classes I-III, with half the cases in classes I and II-a finding similar to Kopelman's original description of all the cases.

The cause of death of the 18 deceased are given in table II. The observed:expected ratios for neoplastic diseases (cancers in this case) and all causes are given in table III.
Table I Current known status of Epping jaundice cases

Table II Causes of death in 18 cases of Epping faundice

\begin{tabular}{ll}
\hline Status & $\begin{array}{l}\text { Number of } \\
\text { individuals }\end{array}$ \\
\hline Still alive & 50 \\
Traced and flagged by NHSCR & 48 \\
Traced but not flagged by NHSCR & 2 \\
Dead with known causes of death & 18 \\
Not traced & 16 \\
Total & 84 \\
\hline NHSCR = National Health Service central registry
\end{tabular}

\begin{tabular}{ll}
\hline Males & Females \\
\hline $\begin{array}{l}\text { Acute myelomonocytic } \\
\text { leukaemia }\end{array}$ & Ceoplastic diseases \\
$\begin{array}{l}\text { Perforated duodenal ulcer } \\
\text { [Cancer of prostate } \\
\text { (registration)] }\end{array}$ & $\begin{array}{c}\text { Carcinoma of common bile } \\
\text { duct }\end{array}$ \\
& Carcinoma of ovary
\end{tabular}

\begin{tabular}{ll} 
Non-neoplastic diseases \\
Ischaemic heart disease & Anorexia nervosa \\
Left ventricular hypertrophy & Ischaemic heart disease \\
Myocardial fibrosis & Coronary artery disease \\
& Aortic valve disease \\
& Cerebral thrombosis \\
& Cerebrovascular disease \\
Ruptured abdominal & aneurysm \\
& Thrombosis leg vein \\
& Chronic bronchitis \\
& (Cerebrovascular stroke- \\
& died aged 90 years + ) \\
\hline
\end{tabular}

Table III Observed and expected deaths for Epping jaundice cases for cancers and all causes questionnaire on two (58\% response rate). Three

\section{DECEASED CASES}

\section{Discussion}

This initial follow up of the "Epping jaundice" cases has traced 68 of the 84 cases $(81 \%)$. Further information on the status of five cases is awaited and $11(13 \%)$ are untraced. Those known to be alive are "flagged" for future follow up.

The causes of death in 18 cases are, by and large, unremarkable. An observed:expected ratio deficit exists for both sexes for both cancers and all causes, the deficit being particularly noticeable for males, all causes. However, the numbers are small and thus little of biological significance can be read into the figures. It is speculative to consider whether those who ate a particular type of wholemeal bread in the 1960 s might be especially health conscious and thus have a lower than expected mortality, or whether this type of bread appealed more to the professional classes I and II, who, for other reasons, have a lower mortality.

The published reports on the health effects of MDA, limited though they are, suggest that the target organs of interest would be the liver and perhaps the bladder. The one death from carcinoma of the bile duct is thus of interest. The tumour developed in this case only six years after the jaundice, but the animal data do point to biliary duct pathology and this tumour is very rare in humans. However, the link with MDA ingestion must remain speculative.

For the surviving cases, one individual had followed a low fat diet since the poisoning due to some fat intolerance, although Kopelman had noted eight cases with fat intolerance two years after the episode. ${ }^{4}$ Visual problems, similar to those reported following ingestion of MDA in potassium carbonate and $\gamma$-butyrolactone ${ }^{5}$ may have occurred in this epidemic. One person reported blurred vision for some three years and another reported suffering from a retinopathy of some sort.

In short, the follow up, a generation on, of the largest episode of MDA poisoning has not revealed an obvious link between current health status and the poisoning episode. One case of biliary cancer and possibly two cases of retinopathy do not provide conclusive evidence of long term health sequelae. The relevance of these findings to those who are occupationally exposed to MDA is doubtful. Occupational exposures are generally of lower dose and longer exposure, with a different route of entry into the body. Nevertheless, in the absence of good occupationally related epidemiology, all accidental exposures to workplace toxins merit follow up. This population will remain under review.

This study was prompted by the IARC statement that MDA was a proven animal carcinogen. Nevertheless, the follow up would not have been possible without the enthusiastic cooperation of the original investigator $\mathrm{Dr}$ Harry Kopelman. He had preserved his original notes of this celebrated episode and to him must go the credit for being able to produce this report.

\begin{tabular}{|c|c|c|c|c|}
\hline & $\begin{array}{l}\text { Observed } \\
\text { (O) }\end{array}$ & $\begin{array}{l}\text { Expected } \\
(E)\end{array}$ & $O / E$ & $\begin{array}{l}\text { One sided } \\
\text { Poisson }\end{array}$ \\
\hline $\begin{array}{l}\text { Males } \\
\text { Females } \\
\text { Both }\end{array}$ & $\begin{array}{r}5 \\
12 \\
17\end{array}$ & $\begin{array}{c}l l \text { causes } \\
15.53 \\
14.97 \\
30.50\end{array}$ & $\begin{array}{l}0.32 \\
0 \cdot 80 \\
0.56\end{array}$ & $\begin{array}{l}0.999 \\
0.813 \\
0.997\end{array}$ \\
\hline $\begin{array}{l}\text { Males } \\
\text { Females } \\
\text { Both }\end{array}$ & $\begin{array}{l}2 \\
3 \\
5\end{array}$ & $\begin{array}{r}\text { Cancers } \\
3.75 \\
3.83 \\
7.58\end{array}$ & $\begin{array}{l}0.53 \\
0.78 \\
0.66\end{array}$ & $\begin{array}{l}0.889 \\
0.736 \\
0.874\end{array}$ \\
\hline
\end{tabular}

